\title{
Family Resilience: A Conceptual Review
}

\author{
Ike Herdiana, Suryanto \& Seger Handoyo \\ Faculty of Psychology University of Airlangga Surabaya \\ ike.herdiana@psikologi.unair.ac.id
}

\begin{abstract}
A family is a primary institution in the society which has dynamic system, and it frequently proceeds especially when its members face a crisis situation. The family's efforts and success to rise from crisis situations are known as family resilience. The purpose of writing this article is to get better understanding about family resilience as a whole concept. This article is based on a review of literature and journals obtained from various sources. The investigation is conducted through the official websites of Google Scholar, PROQUEST, Research Gate, SAGE Publisher and Blackwell Publisher. The results of reviewing the literatures reveal that family resilience is a growing concept. As a concept, family resilience can be seen as trait (nature) and process. The trait review says that family resilience is strongly influenced by several protective factors as the primary key that a family can revive after experiencing adversity. The perspective of family resilience as a process explains that family resilience is built by the success of families using coping strategies to cope with the stressors in their lives. Meanwhile, the framework of family resilience is built through the theory of systems in the family which combines ecological and developmental perspectives. These perspectives are used to view family functions in relation to sociocultural contexts and multi-dimensional family life circles. The perspectives are then widely developed in researches on family resilience. Most studies show that there are many factors that drive a family to reach a post-crisis resilience condition. This factor is called a protection factor. Researches are also interested in revealing protection factor and risk factors that cause a family to continuously be in a crisis situation. Very limited researches that have been conducted in developing a cultural dimension are able to describe how a family achieves resilient conditions in a way that is distinctive or indigenous in accordance with the environmental conditions in which the family resides.
\end{abstract}

Keywords: Family resilience, concept of family resilience, perspective of family resilience, research on family resilience.

\section{INTRODUCTION}

Problems and difficulties are inevitability exist in human life. None of human being in this world lives without problems and difficulties. Individuals will experience the difficulties in a variety of ways. Some individuals can quickly rise up and reflect on the difficulties that they have experienced, but there are many individuals who allow themselves to be 'destroyed' by the inability to resolve difficulties or find it difficult to revive their lives. The condition is popularly known as resilience. Since the 1970s, the focus of health-related researches has shifted from investigating diseases, deficits, or vulnerability to examining individual strengths, assuming individuals are seen as having the resources to enable them to solve their own problems. Resilience as a concept has received great attention in the tradition of developing this individual strength. Referring to its historical roots, the concept of resilience is classified into two disciplines, namely the science of physiology and psychology. This concept is then known and developed primarily in developmental psychopathology research which shows that there is a group of children who remain capable of functioning their strengths optimally in high-risk families. Then in the 1990s, the concept of resilience was acceptable to researchers in science who learned about stress and how the family copes with stress, emphasizing individual and family efforts in coping with the stressors. That is why resilience is one of the themes included in positive psychology, as it elevates the power and potential of the individual to rise from adversity.

As a concept, resilience is then viewed from several perspectives. The perspectives of resilience concept have evolved since the concept was firstly introduced as a construct at the family level. In the traditional view, family resilience is the sum of the resilience performed by family members. A contemporary perspective views family resilience by emphasizing the relational nature of the family as a unit. The perspective also views the relational process that facilitates the survival and growth of families under unfavorable conditions. The great change that has taken place in the development of the concept of family resilience is a different perspective on family resilience as a trait and family resilience as a process. Researchers then make two divisions in their investigation. McCubbin and McCubbin investigate family resilience from a dimensional point of view, the nature of the family to have resistance to crisis situations. On the other hand, as a researcher, Patterson uses the concept of family resilience through a process perspective which focuses on the family's ability to actively mobilize forces during a crisis, which allows the family to re-function its system into the initial condition as before the family experience the stressor or crisis. However, current researches on family resilience tend to emphasize interaction from the point of view of nature and process, in order to results in a holistic understanding.

Resilience has become an important concept in theories and researches related to child development and mental health. Moving the perspective of resilience from the individual level to the family level surely comes with certain reason. However, focusing too much on the resilience experienced by individuals who can survive in families that has lost their functions will blind the researchers and practitioners to find out the factors affecting resilience in families or couples (Walsh, 1996). When we look at individual resilience in a relational context, we will be able to find that resilience appears in a child who are able to overcome their difficulties due to the support and protection given by at least one parent or an adult in his surroundings. All the tough kids in Kauai study have at least one person in their lives who accepts them unconditionally. It is important for them to know that there is someone who can support them to do their business and develop their competence and self-esteem. In addition, Werner notes that all the studies around the world, focusing on children with life problems and difficulties, found that adult's care and companionship during difficult moments has the most significantly positive effect on children's' growth and development. In addition, adaptation is also influenced by experience, which is socially constructed (Gergen, 1990).

Another expert, such as Kagan (1984) found that the consequences of significant emotional experiences, such as the absence of a father or bitter divorce, depend heavily on how the child interprets the event. Kagan is one of several 
researchers who see families as having a positive mediating influence, through the transmission of perceptions and understanding of what is happening to them. Indeed, family relationship is always seen as a most reasonable factor of protection given for its members. Some traumatized people can have the capacity to rise up and experience resilience although they have ineffective family and parenting systems (Gold, 2001, Hooper, 2008). Moreover, the family system may be a risk factor for individuals during childhood and become a protective factor as they grow up in the same individual. In other words, the family system can be very dynamic especially when it is associated with how the individual deals with the problems he or she encounters in their lives. Many factors develop along with the function of a family for the individual. These factors will be reviewed in several ways in this article, through both reviewing conceptual literature and previous studies that have been conducted in relation with family resilience.

This article was written to get better understanding about family resilience as a whole concept based on the specific questions that has been formulated by the researchers, which includes: (1) family resilience as a concept; (2) determinant factor of family resilience; (3) perspective in understanding family resilience; (4) challenges in family resilience research.

\section{METHODS}

This article is based on a review of 24 literatures and journals obtained from various sources. The data were collected by reviewing the official websites of Google Scholar, PROQUEST, Research Gate, SAGE Publisher and Blackwell Publisher. Each article is selected based on specific questions compiled by the author as a first step in understanding family resilience as a concept. These specific questions include: (1) family resilience as a concept; (2) determinant factor of family resilience; (3) perspective in understanding family resilience; (4) challenges in family resilience research. Information related to the four specific questions is collected for further reading. The next step is conducting identification of the main themes presented by the literatures. The data collected from each article are then sorted according to the specific question, and the content is analyzed in order to see its suitability. The less related themes are temporarily separated and not included as part of the analyses. However, whenever the researcher find a theme which provide new information, although it is outside the specific questions formulated, the researchers will keep the information along with the main theme.

\section{RESULTS}

\section{Family Resilience as $A$ Concept}

Family resilience as a concept has developed very rapidly. The development of this concept is based on the number of family resilience studies conducted in a variety of settings. It has been previously explained that there are two classifications that provide complete understanding about family resilience that views resilience as a trait and a process. In its development, these two perspectives are now able to collaborate to produce a complete, thorough understanding of family resilience.

Family resilience can be seen as a trait, meaning we can see the protective factor as the primary key for the family to survive and rise from adversity. This protective factor is found within the family, in the form of positive traits that can encourage families to rise out of the crisis. McCubbin and McCubbin (1988) define family resilience as family characteristics, dimensions and abilities in helping families to solve problems by finding solution and increasing the adaptability of family members with the crisis situations.
Family resilience is a family effort that is followed by adaptability and success in facing pressure, both problems come in the present and future. Resilient families can respond positively to these conditions in a way that is typical, contextdependent, developmental level, the interaction between protection and risk factors and the family's perspective on the problem. (Hawley and DeHaan, 1996). Characteristics and dimensions in the family is known as a family trait. Everything will work well in accordance with the context of the problems encountered. Family trauma is also described as a pattern of positive behavior, the functioning ability of individuals and families that arise under stressful situations, in an attempt to recover by maintaining integrity as a unit and restoring well-being family members and family as a whole (McCubbin and McCubbin, 1996). In addition, Barnard (1994) also uses the term family characteristics as the family capital for resilience. The emphasis of protective factors as a family trait is also biased on the definition of family resilience as a family characteristic associated with the family's ability to encourage individual resilience (Gold, 2001, Hooper, 2008). In addition, the system in the family can also be a risk factor for family members during childhood and become a protective factor in the future when the same individual has matured. Recent studies begin to shift from studies of individual resilience to family resilience (Walsh, 1996, 1998). McCubbin \& Patterson (1982) and Patterson (2002) even describe elements of family warmth, family affection, emotional support, entry as a trait in the family. McCubbin and McCubbin (2001) say that family resilience is a combination of patterns of positive behavior and the functioning of the competencies that each individual has in the family and family as a unit. Positive attitudes and individual competencies are needed to respond to stressful and detrimental conditions. It also determines the ability of the family to recover by maintaining its integrity while maintaining and improving the welfare of family members and family units as a whole.

In addition to some experts who believe on the trait point of view described previously, many other researchers argue that family resilience is a process. The process perspective explains that family resilience is built by the success of families using coping strategies during life's transition, stress or facing adversity (Mc.Cubbin \& McCubbin, 1988, 1996). Activities undertaken in the family run as a process, from meeting with problems to efforts to overcome them. Family responses to face crisis situations are not a single response, but the results of combination of many components that make families feel stronger, more empowered and more confident in developing their problem-solving abilities (Christiansen, Christiansen, \& Howard 1997; HI McCubbin \& MA McCubbin, 1988; Patterson, 2002). Moreover, another expert who believe in the process point of view is Walsh (2003), who defines resilience as the ability to survive and rise from crisis or adversity. Walsh describes it through a dynamic process including positive adaptation towards the crisis. Resilience makes the family develop a positive response to the crisis situation and it encourages families to recover and develop based on the experience of adversity that has been experienced. Family resilience refers to the capacity of families to rebuild from adversity to become stronger and more empowered. Therefore, it can be said that resilience is an active process of building, improving, and optimizing positive responses to crises and challenges (Walsh, 2006). Walsh sees resilience as a dynamic process, meaning that there are components that all move in a clear direction, reaching the power of the family to get out of trouble. The problem itself can be viewed in two ways: (1) as a challenge; or (2) as a risk or crisis. These two perspectives of problem will determine how the family proceeds to maintain its 
function and improve its ability to overcome problems that they experience now and in the future. From 1996 onwards, Froma Walsh is a person who consistently develops the concept of family resilience through his studies and researches. Walsh considers much of the concept that has been exist and makes the concept more complete with the dimensions of family resilience. Family resilience also contributes to the state and well-being of the family and is able to provide protection to difficulties that will undermine family functioning (Heru \& Ryan, 2006).

\section{Determinant Factors that Build Family Resilience}

Family resilience is built by many factors. Masten and Coatsworth (1998) reveal several factors that can build resilience in the family: (1) the length of adverse situations faced by the family; (2) the stage of life when families meet challenges or crises; (3) sources of internal or external support that families use during a challenge or crisis. In this case, Masten and Coatsworth looks at the process of how families can deal with and overcome the crisis based on the characteristics of the existing stressors, how families can develop with different processes adjusted with the level of difficulties they experience, and how families face the problems using the existing social support. It is also used by McCubbin \& McCubbin (1993) in explaining the protective and recovery factors as factors that build family resilience. Protection factors are used by families to maintain family integrity and function. This protection factor comes from many ways, and it is highly dependent on the process of the family using it. In addition, recovery factor is used when families face challenges and this is used by families to rise up from crisis situations. In this case, the recovery process shown by the family also play a significant role in explaining how the family use this recovery factor to overcome the problems encountered.

Meanwhile, the system approach in the family is used by Walsh $(1998,2003)$ to describe how belief systems, organizational processes and communication or problem solving processes work in family systems. The family is seen as a unit in which the system works to remain functioning properly. The family belief system involves the views and approaches the family has in crisis situations, which then affect the potential solutions taken (Walsh, 1998). A positive belief system focuses on how to overcome difficulties through problem resolution, see the linkage and potential for growth, allowing families to unite and see the situation as a "normal" life challenges. Under normal circumstances, families are able to evaluate the potential of resources and create positive views and expectations. The second main process is organizational processes, a factor that focuses on promoting family resilience through the flexibility, connectedness, and identification of available resources (Walsh, 1998). The third process is communication or problem solving processes which focuses on developing open communication within the family, which is believed to increase the level of trust and mutual respect and it also help the family to accept the differences between family members and the freedom to express emotions (Walsh, 1998). Then Walsh (2003) presents a concept map framework to identify and explain key family processes that can reduce stress in overcoming high-risk situations, healing, rising up from the crisis and strengthening family bounding to face adversity over the long term. This theory is the basis of two key premises: (1) the individual is someone who will understand and learn many things from the family environment and social world; (2) the whole family has the potential for resilience and this principle can be maximized by identifying and building the key strengths and resources within the family (Walsh, 1998). Next Oh and Chang (2014) and Black and Lobo (2008) conducted research on factors that built family resilience based on three key family resilience processes developed by Walsh. The results show that family resilience factors as proposed by Walsh appear in the context examined by Oh and Chang (2014) and Black and Lobo (2008).

According to Black and Lobo (2008), every family, regardless of the ethnic, has differences in family resilience, setbacks, and severity of risk. There is no key factor, the most effective protective and recovery factors a family can take. Nevertheless, recent research reviews and literature have identified the prominent attributes of resilient and healthy families. These factors include: positive outlook, spirituality, harmonious family members, flexibility, family communication, financial management, family time, recreation, routine and ritual, and social support.

Table 1. Characteristics of Family Resilience, Protection Factors and Recovery Factors

\begin{tabular}{|c|c|}
\hline Resilience Factor & Family Characteristic \\
\hline Positive Outlook & $\begin{array}{l}\text { Confidence and optimism, repertoire of } \\
\text { approaches, sense of humor }\end{array}$ \\
\hline Spirituality & $\begin{array}{l}\text { Shared interval value system that gives } \\
\text { meaning to stressors }\end{array}$ \\
\hline $\begin{array}{l}\text { Family member accord } \\
\text { Cohesion; }\end{array}$ & $\begin{array}{l}\text { Cohesion, nurturance, authoritative } \\
\text { discipline, avoidance of hostile parental } \\
\text { conflict }\end{array}$ \\
\hline Flexibility & $\begin{array}{l}\text { Stable family roles with situational and } \\
\text { developmental adjustments }\end{array}$ \\
\hline Family communication & $\begin{array}{l}\text { Clarity, open emotional expression, and } \\
\text { collaborative problem solving }\end{array}$ \\
\hline $\begin{array}{l}\text { Financial management } \\
\text { Sound }\end{array}$ & $\begin{array}{l}\text { Sound money management, family warmth } \\
\text { despite financial problems }\end{array}$ \\
\hline Family time & Creates togetherness with daily tasks \\
\hline Shared recreation & $\begin{array}{l}\text { Develops child social and cognitive skills; } \\
\text { cohesion and adaptability }\end{array}$ \\
\hline Routines and rituals & $\begin{array}{l}\text { Embedded activities that promote close } \\
\text { family relationships; maintenance even } \\
\text { during family crisis }\end{array}$ \\
\hline Support network & $\begin{array}{l}\text { Individual, familial, and community } \\
\text { networks to share resources; especially } \\
\text { important for families in poverty }\end{array}$ \\
\hline
\end{tabular}

*Source : A Conceptual Review of Family Resilience Factors (Black\&Lobo, 2008)

\section{System Theory to Understand Family Resilience}

An important statement expressed by Walsh (1996), as one of the experts who developed the concept of family resilience, is that the family resilience framework is built through family systems theory which is a combination of ecological and developmental perspectives. The perspective is used to view family functions in relation to sociocultural contexts and multi-dimensional family life circles. The ecological or sociocultural perspective considers resilience closely related to the larger individual factors, families and social systems of society. Individual problems can arise from biological, psychological, social and spiritual orientations. The symptoms of distress experienced by individuals can come from biological aspects, such as severe pain or neurological disorders. Problems can also arise due to the influence of sociocultural variables, such as poverty and discrimination experienced by families and communities that are at high risk for the emergence of problems.

The symptoms of family members may arise because of events that contain crises, such as sexual violence, tragic loss, or the consequences of disasters on a large scale. Stress experienced by the family will be exacerbated by family failure in overcoming the unpleasant situation. Families, peer groups, communities, schools, workplaces and other social systems are the ones that will support resilience. The holistic or multi-dimensional approach discusses about context variation, identifies key elements in a crisis situation and sees it through a particular, unique perspective, resources and 
challenges that the family has. This point of view is also necessary to consider the condition of children and adults who have an effect on risk factors and protection against the awakening of resilience. This is supported by Bronfenbrenner's (1979) assertion which views that family, peer groups, school or work arrangements, and larger social systems can be seen as a means of viewing social competence. This social competence will assist the individual in solving all problems or crises faced. Seligman (1990) recognizes that positive views need to be encouraged in an environmental context. Living conditions must offer rewards and achievements. Experiences such as violence, or job loss despite good performance, can lead to cynicism and despair. Rutter (1987) warns that in order to understand and encourage psychosocial resilience and protective mechanisms, we must know the interaction between things that happen within the family and the things that happen to the political, economic, social, and racial climate in which individuals develop.

Understanding family resilience can also be seen from a developmental perspective. Rather than just discussing about a set of trait, or attributes that already exist, the ability of individuals to adapt and cope with the difficulties they encounter can be done by observing everything in multiprocess, from time to time. Many forms of psychosocial stress are not as simple as we see, even small but complex stimuli can change the past and future history of the individuals (Rutter, 1987). Our success in dealing with increasingly complex problems over the time is not determined by a single coping response, because the most important is that we are able to use various coping strategies to find challenges from the difficulties we face (Pearline \& Schooler, 1978). A study found that risk factors do not necessarily make people difficult to adapt, nor make a person predicted to survive (Felsman \& Vaillant, 1987). Garmezy (1987) conducted a study to understand the three components that describe the relationship of psychosocial and biological factors in formulating adaptability in stressful situations. The three components are: (1) vulnerability or predisposition; (2) conditions that become trigger or potentially cause stress; and (3) protective factors that support resilience during stress and support a person's ability to withstand the stress that they experience. By the time, the process then incorporates larger individual, family and social environment factors to build resilience and the success of a person overcoming the problem so as to avoid family dysfunction or disturbance. Stages of development will provide a balance between stressful events with protective mechanisms that can increase resilience. The influence of family, peers, and greater social strength can also be found at every stage of development. The orientation of the family life circle sees the family as a system on which during the lifetime will move forward for all family members and through generations. Essential developmental perspectives for understanding and supporting family resilience include: (1) families have varied ways of building resilience and overcoming challenges over time; (2) accumulating stressors can make families overwhelmed; (3) the impact of the crisis experienced by the family varies greatly in relation to the timing of crisis in the life cycle of individuals and families; (4) family past experience in responding and facing difficulties can be used as reference to face of adversity or may serve as a model for survival in the present or future.

\section{Challenges on Researches about Family Resilience}

In essence, studies conducted by experts or scientists who have a great interest in family studies have the same goal of testing, verifying or strengthening a concept or construct. The definition or limitation of a concept or construct may be developed and be more detailed in accordance with the latest findings of the research results on the concept / construct. Recent research on resilience appears to be shifting from individual resilience to family resilience (Walsh, 1996, 1998). During this period, resilience is often predicted to occur only at the individual level, despite the context of family dysfunction. Whereas family resilience when viewed systemically, can also be associated with efforts to strengthen individuals and families. In the context of resilience, familyrelated factors are not always related to family difficulties or traumas, but also other elements such as warmth, affection, and emotional support in the family (McCubbin \& Patterson, 1982; Patterson, 2002). Although a child often gets violence in his family, the elements of the family may remain. Thus, a child may remain resilient despite the continuing misfortune. Walsh (1998) argues that if parents cannot provide a positive climate, relationships with other members of the family, such as older siblings, grandparents, and other relatives can serve a missing family function. Walsh's opinion is in line with Werner and Smith's research experience (1970). Lietz (in Becvar, 2013) writes that early resilient research was heavily influenced by Werner and Smith (2001) who for 40 years studied high-risk teenagers. The researchers conducted a longitudinal study followed by 698 babies born on Kauai Island within 1 year. One-third of the samples were identified as high-risk. Such children (a) experience perinatal stress, (b) are born in poverty, and (c) are raised in disputed family, parental, addictive, or mental health conditions. Samples from adolescent participants are then assessed every 10 years. This study uncovered a set of emerging protective factors, such as maintaining a relationship with at least one caring adult, who helped many of these children to successfully overcome challenges and eventually developed into well-functioning. Most important in this study is how we are encouraged to examine how risk factors and protectors work together for better functioning (Garmezy, 1993; Garmezy, Masten, \& Tellegen, 1984; Luthar, 1991; Masten \& Coatsworth, 1998). These studies then call us a conclusion that individual success to overcome difficulties is determined by two actors, personal traits and protective factors in family and social context (Werner, 1993; Wetner \& Smith, 1992).

Further researches on family resilience are increasingly appeared. Some instruments that support the research are explained by the researchers in clear stages of construction. In addition, this family resilience research is also observed in many contexts and methodologies. Some of the studies reviewed in this article are based on their context, methodology and instruments. 
Table 2. Review of the Previous Researches Based on Context, Methodology and Instruments

\begin{tabular}{|c|c|c|c|c|}
\hline No & Title/ Researcher & Contexts & Methodology & Instruments \\
\hline 1 & $\begin{array}{l}\text { Psychometric properties of the Family } \\
\text { Resilience Assessment Scale:A Singaporean } \\
\text { perspective. Chew, J \& Haase,A.M.,2016 }\end{array}$ & Singapore & Quantitative & (FRAS), (RSS), Illness Severity \\
\hline 2 & $\begin{array}{l}\text { Family functioning, resilience, and depression } \\
\text { among North Korean refugees Nam, B., et al., } \\
2016\end{array}$ & North Korea & Quantitative & $\begin{array}{l}\text { Korean version of Family Adaptability and } \\
\text { Cohesion Evaluation Scale, Korean } \\
\text { version of the Connor-Davidson Resilience } \\
\text { Scale, The Korean version of the Center } \\
\text { for Epidemiologic Studies Depression }\end{array}$ \\
\hline 3 & $\begin{array}{l}\text { Living with a parent with dementia : A family } \\
\text { resilience study Deist,et. al.,2017 }\end{array}$ & South Africa & $\begin{array}{l}\text { Cross } \\
\text { Survey }\end{array}$ & $\begin{array}{l}\text { FACI8, F-COPES, } \\
\text { FPSC,FTR,RFS,SSI; interview semi- } \\
\text { structured interview to } 21 \text { participants }\end{array}$ \\
\hline 4 & $\begin{array}{l}\text { Empowering The 'Cheerers': Role of } \\
\text { Surgical Intensive Care Unit Nurses in } \\
\text { Enhancing Family Resilience (Ellis, L et } \\
\text { al.,2017) }\end{array}$ & America & Qualitative & Interview and FGD \\
\hline 5 & $\begin{array}{l}\text { Resilience in families in which a member has } \\
\text { been diagnosed with schizophrenia } \\
\text { (Bishop,M\&Greef, A.P,2015) }\end{array}$ & South Africa & Mixed Method & $\begin{array}{l}\text { FACI8, FHI, FTRI, SSI, F-COPES,FPSC, } \\
\text { RFS, Open Interview }\end{array}$ \\
\hline 6 & $\begin{array}{l}\text { Family Resilience and Midlife Marital } \\
\text { Satisfaction (Huber,C.H. et al.,2010) }\end{array}$ & $\begin{array}{l}\text { Various cultures from } \\
\text { America }\end{array}$ & Quantitative & $\begin{array}{l}\text { IFPF, } \\
\text { MSQFOP }\end{array}$ \\
\hline 7 & $\begin{array}{l}\text { Families of Children With Down Syndrome:.: } \\
\text { Responding a Change in Plans With } \\
\text { Resilience. (Riper,M.V.,2007) }\end{array}$ & America & Quantitative & $\begin{array}{l}\text { Individual Adaptation, Family Adaptation, } \\
\text { Family Demands, FILE,FIRM, FPSC, F- } \\
\text { COPES }\end{array}$ \\
\hline 8 & $\begin{array}{l}\text { Male prisoners' family relationships and } \\
\text { resilience in resettlement. (Markson,L. et al., } \\
\text { 2015) }\end{array}$ & United Kingdom & Qualitative & Interview \\
\hline 9 & $\begin{array}{l}\text { Resilience model for parents of children with } \\
\text { cancer in mainland China-An exploratory } \\
\text { study. (Ye,Z.J. et all, 2017) }\end{array}$ & China & Quantitative & $\begin{array}{l}\text { Resilience Model for Parents of Children } \\
\text { with Cancer (RMP-CC) }\end{array}$ \\
\hline 10 & $\begin{array}{l}\text { Living with a parent with dementia : A family } \\
\text { resilience study. Deist et al., 2015) }\end{array}$ & $\begin{array}{l}\text { Western Cape, South } \\
\text { Afrika }\end{array}$ & $\begin{array}{l}\text { Mixed Method Cross } \\
\text { Sectional }\end{array}$ & $\begin{array}{l}\text { FACI8, F-COPES, FHI, FPSC,FTRI, } \\
\text { RFS,SSI, semi structured interview }\end{array}$ \\
\hline 11 & $\begin{array}{l}\text { Natural Disasters : An Assessment of Family } \\
\begin{array}{l}\text { Resiliency Following } \\
\text { (Harkbart,M., }\end{array} \\
\text { Wetchler,J.,Flannery, M., 2012) }\end{array}$ & America & Quantitative & F-COPES, FHI, SRM, LoRM \\
\hline 12 & $\begin{array}{l}\text { Resilience of Young Women as Human } \\
\text { Trafficking } \\
\text { Victims (Yunita Sari and Khairunnisa, 2014) }\end{array}$ & West Java Indonesia & Descriptive Analysis & $\begin{array}{l}\text { Scale of resilience and Semi Structured } \\
\text { Interview based on Grothberg Theory. }\end{array}$ \\
\hline 13 & $\begin{array}{l}\text { Family Resilience in families where a parent } \\
\text { has a mental illness (Power,dkk, 2016) }\end{array}$ & $\begin{array}{l}\text { Caucasian } \\
\text { Australia/British/Europe }\end{array}$ & Qualitative & Depth Interview \\
\hline 14 & $\begin{array}{l}\text { Cultivating Resilience in Families Who } \\
\text { Foster : Understanding How Families Cope } \\
\text { and Adapt Over Time (Lietz,C.A., Julien- } \\
\text { Chinn, F.J., Geiger, J.M., Piel, M.H., 2016). }\end{array}$ & America & Qualitative & $\begin{array}{l}\text { Narrative Interview and open ended } \\
\text { questionnaire }\end{array}$ \\
\hline 15 & $\begin{array}{l}\text { Qualitative Study of Resilience of Family } \\
\text { Caregivers for Patients with Schizophrenia in } \\
\text { Japan (Amagai,M.,Takakashi,M.,Amagai,F., } \\
\text { 2016) }\end{array}$ & Japan & Qualitative & Phenomenological Interview \\
\hline
\end{tabular}


Based on the article and journal review of previous researches on family resilience, it can be explained that researches on family resilience can be applied in diverse contexts. The resilient researches have been conducted in developed and developing countries, as well as in a multiethnic country. In addition, the methodology used in the researches is also varied, some researches only use one research methodology, but the majority of the researches were conducted using mixed method. Similarly, the instruments used in the researches are varied and show rapid development. Some instruments are developed with high validity and reliability in order to really measure the conditions to be measured. Some others also use qualitative research data collection techniques which are not only limited to in-depth interviews but also through the activities of Focus Group Discussion (FGD).

The subjects of the studies on family resilience were chosen according to the research objectives. What makes these studies more interesting is the problems or difficulties experienced by the subjects do not depend on one type of adversity, but in many types of misfortunes perceived as stressors, such as stress on certain occupations (e.g. nurses and caregivers) married couples, and inmates. Most of the researches are conducted in families in which one of their family members has degenerative pain, congenital defects, and severe mental illness. The results show that many factors are associated or emerged as new findings which can create family resilience.

In addition, several studies of family resilience compiled by Anne I.H.Borge, Frosso Motti-Stefanidi, Ann S.Masten (2016) show that in high-risk environments, it was found that protection is the most frequently appeared family functions. The researchers focus on investigating resilience on the selected samples with high-risk lives, but protective factors could not be detected. The study discusses how protection factors work to improve family function and how it causes the risks or difficulties get worse due to the accumulated risks experienced by some families (Borge, et.al, 2016). Another study was conducted by Anagnostaki and colleagues who conducted a cross-sectional study by comparing the academic achievement of immigrant adolescents from Albania who moved to high school with their mostly Greek teenage friends and explained the role of personal differences (self-efficacy and locus of control) and family factors (parental school involvement, father and mother education, parental support) in measuring differences in individual and group achievement. The results indicate that personal and family resources are correlated with academic achievement, regardless the immigrant status the subjects have. Immigrant status and low social status are still seen as distinctive risk factors for students with low academic achievement. (Borge, et.al, 2016)

Several studies have been conducted using family resilience variables as the main variables, extracted from component analysis of sociocultural context, theoretical framework, attributes, antecedents (stressor and facilitator) and the consequences analyzed by Oh and Chang (2014). The goal is to analyze the status of family resilience concept for other research needs in the future. The data were collected from 6 electronic databases through the searching key word 'family resilience'. After collecting the data, the data sources selected are 17 quantitative researches, 17 qualitative researches and 4 mixed research methods. The results of the analysis show that there are six dimensions in family resilience, namely: (1) collective beliefs; (2) connectedness; (3) a positive way of life; (4) total empowerment, including obtaining support from others and having the ability to identify and provide support to others; (5) open communication pattern; (6) able to solve problems collaboratively. Meanwhile, there are three antecedent variables which are found to influence family resilience, namely: (1) acceptance of disequilibrium condition; (2) spirituality / belief / religiosity system; (3) family strength when experiencing big problems. Analysis is also carried out on the consequences of family resilience which include: (1) acceptance of the situation; (2) change in the way of viewing life; (3) quality improvement in relation; (4) reinforcement of the properties that promote resilience; (5) increase the outcomes associated with efforts to stay healthy. Interestingly from $\mathrm{Oh}$ and Chang's analysis, this present study tries to elaborate the data obtained comprehensively. The antecedent dimensions and variables are taken from studies using quantitative methods, while data on the consequences of family resilience are applied in qualitative researches. Both techniques will provide significant results that will help future researchers to examine family resilience more comprehensively.

\section{DISCUSSION}

As a concept, family resilience can be seen as trait (nature) and process. The trait review says that family resilience is strongly influenced by some protective factors as the primary key that a family can revive after experiencing adversity. This protective factor comes from within the family, in the form of positive traits that can encourage families to rise out of the crisis. The point of view of family resilience as a process explains that family resilience is built by the success of families using coping strategies to cope with the stressors that they encountered in their lives. All activities undertaken in the family work as a process, beginning with the first time to meet problems to attempt to overcome them. Family responses in crisis situations are the interaction of many components that make families feel stronger, more empowered and more confident in developing their problemsolving abilities. However, family resilience cannot be viewed from a single point of view. However, the positive factors that come from families will interact with each other into a process of how resilience develops in a family. Therefore, it seems less appropriate if we separate the discussion on each view.

Family resilience is built because of several factors such as the length of a family experiencing adverse situations, the stages of family life when they have to deal with crisis and social support received by the family during the crisis. In addition, the factors disclosed by Walsh (1998) include belief system factors, organizational processes and communication / problem solving processes. These three factors work in a system called family. These factors are evolving along with the emergence of many studies related to family resilience variables. Moreover, the current research on family resilience has been widely developed in various contexts and methodologies. Unfortunately, the researchers cannot provide more comprehensive explanation on how the cultural background encourages the formation of family resilience in a distinctive and indigenous way. A sociocultural perspective is one way of looking at how resilience can be built within a family. This allows family resilience to be explained through the mechanism or process used by the family to cope with the problem experienced, and how they select the coping strategies appropriately to the condition of their lives. Social support received by the family on a particular setting or culture should also be able to provide more specific data. This will enrich the study of family resilience as a grand and whole concept.

The study of family resilience should also be the basis for developing an intervention of how to strengthen family functions. It can be applied not only in families with high 
living risk, but also for families with a normal life. Dynamics within the family are very likely to cause a change of orientation that causes the family to be dysfunctional and affect other family members. Currently, families can be the protection factor, but it will not stay longer. In the future, a family can also be a risk factor. However, individual efforts to become resilient to the crisis are due to family support. Similarly, family system will be not stable as individuals experience a crisis. Efforts to intervene will be directed at strengthening relations and consistency in fostering social support within the family itself. Thus, the concept of family resilience is not only established by the results of scientific researches but also by the empirical experience gained from practitioners' notes experienced by families, especially when they are in crisis situation.

\section{CONCLUSION}

This conceptual review of family resilience leads to an awareness that research needs to be conducted in various settings to reinforce this concept. Some of the studies reviewed by the authors are still dominated by researches in the field of health, although there are also researches in the field of job and social context. Family resilience has a multidimensional concept that continues to grow rapidly in accordance with the many results of researches on the concept. Cultural differences and other demographic factors are important to be examined more deeply in order to get a comprehensive picture and details on how a family can revive after experiencing adversity. The researchers consider the importance of explaining how protective factors work well in the family to produce healthy family conditions and what effective coping strategies should be applied in order to overcome the life problems. Family dynamics such as family members' positive responses to deal with stressors have a great impact on the family's ability to cope with crisis situations, and this is strongly influenced by the socio-cultural factors in which the family lives. Thus, the concept of family resilience will experience dynamic changes because it is accompanied by specific and distinctive conditions that occur in families, especially when they face less favorable situations.

\section{REFERENCES}

Amagai, M. (2016). Qualitative Study of Resilience of Family Caregivers for Patients with Schizophrenia in Japan, 307-312

Becvar, D.S. (2013). Handbook of Family Resilience. DOI. 10.1007/978-1-4614-3917-2. Newyork : Springer.

Black, K., \& Lobo, M. (n.d.). A Conceptual Review of Family Resilience Factors. https://doi.org/10.1177/1074840707312237

Borge, A. I. H., Motti-stefanidi, F., \& Masten, A. S. (2016). Resilience in developing systems: The promise of integrated approaches for understanding and facilitating positive adaptation to adversity in individuals and their families. European Journal of Developmental Psychology, 13(June), https://doi.org/10.1080/17405629.2016.1188496

Chew, J., \& Haase, A. M. (2016). Psychometric properties of the Family Resilience Assessment Scale: A Singaporean perspective. Epilepsy and Behavior, 61, 112-119. https://doi.org/10.1016/j.yebeh.2016.05.015

Ellis,L.et all. (2016). Empowering The 'Cheeres' : Role of Surgical Intensive Care Unit NursesIn Enhancing Family Resilience. American Association of Critical Care Nurses.

Deist, M. D. and Greeff, A. P. (2016). Resilience in Families Caring for a Family Member Diagnosed with Dementia. Educational Gerontology, 41: 93-105, 2015, 85(September).

https://doi.org/10.1177/1471301215621853
Hooper, L. M. (2008). Individual and Family Resilience: Definitions, Research, and Frameworks Relevant for All Counselors. Alabama Counseling Association Journal, 35(1), 19-26. Retrieved from http://eric.ed.gov/?id=EJ875400

Henry, C. S., Sheffield Morris, A., \& Harrist, A. W. (2015). Family Resilience: Moving into the Third Wave. Family Relations, 64(1), 22-43. https://doi.org/10.1111/fare.12106

Huber, C. H., Navarro, R. L., Womble, M. W., \& Mumme, F. L. (2010). Family Resilience and Midlife Marital Satisfaction. The Family Journal, 18(2), 136-145. https://doi.org/10.1177/1066480710364477

Hooper, L. M. (2008). Individual and Family Resilience: Definitions, Research, and Frameworks Relevant for All Counselors. Alabama Counseling Association Journal, 35(1), 19-26. Retrieved from http://eric.ed.gov/?id=EJ875400

Isaacs, S. A., Roman, N. V., Savahl, S., \& Sui, X.-C. (2017) Adapting and Validating the Family Resilience Assessment Scale in an Afrikaans Rural Community in South Africa. Community Mental Health Journal, $0(0), 0$. https://doi.org/10.1007/s10597-017-0091-1

Markson, L., Loesel, F., Souza, K., \& Lanskey, C. (2015). Male prisoners' family relationships and resilience in resettlement. Criminology \& Criminal Justice, 15(4), 423-441. https://doi.org/10.1177/1748895814566287

Bishop,M, Greeff,A.P. (2015). Resilience in Families in Which a Member Has Been Diagnosed Wisk Schizoprenia. Journal of Psychiatric and Mental Health Nursing, 2015, 22, 463471

McCubin, H,I., Thompson, A.I., \& McCubbin, M. (2001). Family Measures: Stress, Coping, and Resiliency. Hawai:Kamehameha Schools.

Nam, B., Kim, J. Y., DeVylder, J. E., \& Song, A. (2016). Family functioning, resilience, and depression among North Korean refugees. Psychiatry Research, 245, 451-457. https://doi.org/10.1016/j.psychres.2016.08.063

Oh, S., \& Chang, S. J. (2014). Concept Analysis : Family Resilience, (December), 980-990.

Patterson, J. M. (2002). Integrating family resilience and family stress theory. Journal of Marriage and Family, 64(2), 349360. https://doi.org/10.1111/j.1741-3737.2002.00349.x

Riper,M.V. (2007) Familiesof Children With Down Syndrom : Responding a Change in Plans With Resilience. DOI : 10.1016/j/pedn.2006.07.004. Vol.22.No.2.

Simon, J. B., Murphy, J. J., \& Smith, S. M. (n.d.). Understanding and Fostering Family Resilience. https://doi.org/10.1177/1066480705278724

Southwick,S.M. et all. (2011). Resilience and Mental Health Challenge Across The Life Span. New York : Cambridge.

Walsh, F. (1996). The concept of family resilience: Crisis and challenge. Family Process, 35(3), 261-281. https://doi.org/10.1111/j.1545-5300.1996.00261.x

Walsh, F. (2016). Family resilience: A developmental systems framework. European Journal of Developmental Psychology, 42(1), 1-18 https://doi.org/10.1080/17405629.2016.1154035

Ye, Z. J., Qiu, H. Z., Li, P. F., Liang, M. Z., Wang, S. N., \& Quan, X. M. (2017). Resilience model for parents of children with cancer in mainland China-An exploratory study. European Journal of Oncology Nursing, 27, 9-16. https://doi.org/10.1016/j.ejon.2017.01.002 